\title{
Characterization of Oxygen Transmission Rate of Oak Wood Species Used in Cooperage
}

\author{
María del Alamo-Sanza ${ }^{\dagger}$, Luis Miguel Cárcel ${ }^{\ddagger}$, Ignacio Nevares ${ }^{{ }^{*}}$ \\ `Departamento de Química Analítica, UVaMOX-Universidad de Valladolid, \\ ${ }^{\ddagger}$ Departamento de Ingeniería Agrícola y Forestal, UVaMOX-Universidad de Valladolid, \\ E.T.S. Ingenierías Agrarias, Avda de Madrid, 50, 34001 Palencia (Spain) \\ *Corresponding author (Tel: +34-979-108384; Fax: +34-979-108302: E-mail: \\ inevares@iaf.uva.es)
}

\begin{abstract}
The oxygen that wine receives while aged in barrels is of interest because it defines the reactions that occur during aging and therefore the final properties of the wine. This study is intended to make up for the lack of information concerning the oxygen permeability of eight different woods of Quercus alba and Quercus petraea commonly used. In addition, it shows how oxygen transfer evolves with the liquid contact time when tested under similar aging conditions to those in wine barrels. French oak woods permitted a higher oxygenation rate than American ones in all cases. A decrease in the oxygen entry caused by impregnation of the wood during the process was observed in all the species studied. This process is determined by the thickness of the flooded wood layer containing free water, although differently in the two species, possibly due to the anatomical structure and the logging process for each.
\end{abstract}

KEYWORDS: American oak, French oak, grain, oxygen transfer rate, oak stave, oxygen permeation, barrel

\section{INTRODUCTION}

Oxygen plays an important role in the aging of wine in barrels because, during the aging time, it influences the reactions that occur between the compounds in the wine and those that the wood provides. For a long time, it has been claimed that wine only has oxygen available from the filling of the barrels and the racking during aging. Recently and as a continuance of the studies carried out by Piracci, ${ }^{1}$ wood degasification has been studied as an initial and significant contribution of oxygen to wine. ${ }^{2}$ It has been hypothesized that the inner surfaces of the staves of the barrels become clogged by the precipitation of colored material and tartrates, ${ }^{3}$ which would prevent oxygen entry over time. Other authors have postulated that soluble ellagitannins in wet wood act as scavengers of oxygen entering the barrel, thereby preventing the oxygen from reaching the wine. ${ }^{4,5}$ Vivas and Glories ${ }^{6}$ analyzed two French oak barrels for six months and found that oxygen entered the wine primarily through the joints between staves $(63 \%)$ and the head $(21 \%)$, while the wood accounted for the remaining $16 \%$ of oxygen entry.

Recent studies evaluating eight barrels of American and French oak have shown that oxygen entering the wood can represent up to $70 \%$ of the total oxygen (in French oak); thus, it is also necessary to consider wood as a primary route of oxygen entry into the wine within a barrel. ${ }^{7}$ Dry wood is more permeable to oxygen than wet wood because the diffusion coefficient of oxygen in air is 10,820 times greater than the diffusion of oxygen in water at $15^{\circ} \mathrm{C} .^{8}$ Therefore, Vivas et al., ${ }^{9}$ analyzing 2-mm thick samples for a week, found that dry wood can allow between 20 and 100 times more oxygen to pass than wet wood. Given the difficulties of the measurement and the variability of results from wet wood, the 
experiment was performed with dry wood, a situation that does not reproduce the barrel scenario. A previous study found ${ }^{10}$ that oxygen did pass through either dry or wet oak wood, and the study visualized the movement of oxygen when it crosses the stave from the outside to the inside of the barrel. Recently, another study found that oxygen permeation, that is the rate of entry or the oxygen transmission rate (OTR) into the inside of the barrel, changes with the liquid-wood contact time and decreases following a power-law curve. ${ }^{11}$ On the other hand, the same study mentions that no studies that analyze the effect of the type of wood, the origin of the wood or the wood grain on oxygen entry through wood in conditions similar to a barrel-aging process have been found. The results from Vivas study ${ }^{9}$ showed that fine-grain dry wood (Allier, $1.2 \pm 0.7 \mathrm{~mm} /$ year) is more permeable to oxygen than medium-grain dry wood (Vosgos, $3.4 \pm 0.5 \mathrm{~mm} /$ year) in samples of various thicknesses $(2,4,8$ and $16 \mathrm{~mm})$.

The objective of this study is to evaluate the OTRs of different woods under conditions functionally similar to those of a barrel oak stave, taking into account the variation in the oxygen diffusion coefficient that occurs in wood during aging. The results indicate that, under aging in barrel conditions, French oak wood lets more oxygen into the wine than American oak wood and that finer-grain woods allow more oxygen to enter than the same wood with a medium grain. Furthermore, it has been confirmed that, in the different species of oak, the thickness of the flooded wood determines the decrease in the oxygen entry rate through the wood by reducing its diffusivity as a flooded porous solid.

\section{MATERIALS AND METHODS}

In this study different staves were analyzed with the aim of determining their oxygen transmission rates and their impregnation profiles with the barrel liquid over an aging time.

Toasted woods. Enough homogenous rough staves of eight types of oak wood were selected, according to their origin and grain, to build a barrel following the usual process of bending and medium toast at the Tonelería Duero cooperage (Aranda de Duero, Spain). Table 1 shows the characteristic grains according to cooperage classification, measured grain and density of the studied oak woods from Quercus petraea (Matt.) Liebl. and Quercus alba L. Subsequently, the barrel was disassembled, and the staves were sent to our center for study. All of the samples were stored in the barrel room under ambient conditions of $15^{\circ} \mathrm{C}$ and $75-80 \%$ relative humidity, maintaining $9-11 \%$ moisture content $(\mathrm{MC} \%)$ in the woods.

Density, porosity and moisture content profile of oak woods. The densities $(\rho)$ of the eight types of wood were calculated following the protocol of ISO 13061-2:2014, ${ }^{12}$ for which a portion of wood (i.e. a wood sample) was extracted from each of the staves of the different woods (Figure 1).

The porosity $\left(v_{a}\right)$ was calculated according to Siau ${ }^{13}$ from the oven dry cell-wall specific gravity $\left(G_{o}{ }^{w}\right)$, assuming 1.53 as the true value for water displacement, compaction of bound water being neglected, specific gravity of wood $(G)$ and valid at any moisture content (MC) (Eqn. 1).

$$
v_{a}=1-G\left(\frac{1}{G_{o}{ }^{w}}+0.01 \cdot M C\right)=1-G(0.653+0.01 \cdot M C)
$$

The density and porosity results are presented in Table 1 .

In five of the oaks, two American and three French (Figure 1), the wetting profile was calculated. For this calculation, 4 portions of each wood (or wood samples) were extracted 
from each of the staves and were maintained in contact with model wine (14\% alcohol, $\mathrm{pH}$ $3.5)$ only on the toasted side of the stave reproducing similar aging conditions to those in barrels, until reaching 7, 21, 42 and $105 \mathrm{~d}$ of wetting. At each of those time points, every wood sample was sliced into approximately 25 pieces, with an average thickness of $1 \mathrm{~mm}$, parallel to the toasted face in contact with the model wine. The MC of each of the extracted pieces was calculated according to ISO-13061-1:2014, ${ }^{14}$ which allowed the MC of the wood at different distances from the face in contact with the model wine and at different times during the first three and a half months of aging to be determined.

In all of the cases, the tested wood pieces measured $40 \mathrm{~mm}$ in diameter with thicknesses of $27 \mathrm{~mm}$, similar to that of $225 \mathrm{~L}$ barrel staves.

Measurement of dissolved oxygen. The dissolved oxygen was measured simultaneously in eight measuring chambers with two FirestingO2-4 oxygen meters (Pyroscience $\mathrm{GmbH}$, Aachen, Germany) equipped with 4 channels each and trace oxygen sensors (measurement range: $0-10 \% \mathrm{O}_{2}$, limit of detection: $0.004 \% \mathrm{O}_{2}$ ). The sensor was located inside the measuring chamber in direct contact with the wine. Via an optical fiber luminescent measurements were taken through a transparent surface to which the sensor was attached. The oxygen systems were calibrated using a conventional two-point calibration in the model wine, saturated with nitrogen (cal 0$)$ and at a second calibration value between $5 \%$ $10 \%$ air saturation. A calibration gas mixture with $2.001 \%( \pm 0.5 \%)$ pure oxygen gas in nitrogen $(9.55 \%$ air-sat) was used as the second calibration standard (Carburos Metálicos, Spain). All of the $\mathrm{pO}_{2}$ measurements were corrected to compensate for interference from ethanol according to the model developed in previous studies. ${ }^{15}$ To evaluate the oxygen concentration in mg/L, Henry's law was applied, and the solubility of oxygen in hydroalcoholic mixtures was used ${ }^{16}$ to avoid underestimation when oxygen solubility in water was used (unpublished results).

Oxygen transmission rates of the wood. The oxygen transmission rates of the eight oak woods were analyzed; therefore, it was necessary to extract a new different portion of oak wood (or wood samples) from each of the staves to determine their OTRs at eleven different time points of aging $(7,8,9,17,28,35,45,53,60,82,210 \mathrm{~d})$ (Figure 1) the first measurement being after $7 \mathrm{~d}$ once the desorption process of the air content of the wood had finished. ${ }^{17}$ The samples were maintained in contact with model wine (14\% alcohol, $\left.\mathrm{pH} 3.5\right)$ only on the toasted side of the stave reproducing similar aging conditions to those in barrels, until the different $d$ of wetting were reached. At each of those time points, the OTR of every wood sample was analyzed. A total of 88 OTR tests were carried out on the wood samples. A device extensively described in previous studies ${ }^{18,19}$ was used to determine the OTRs of the different materials in contact with gas and/or liquids. The steady-state permeation of gases through a material with the thickness $d$ was calculated with the following simple equation based on Fick's first law:

$$
J=P \cdot \frac{\Delta p O_{2}}{d}
$$

where the flux $J\left(\mathrm{~m}^{3}\right)$ is the volumetric flow of gas transported per unit time (s) through a unit surface area $\left(\mathrm{m}^{2}\right)$; according to Eqn. (2), the flux proportional to the constant partial pressure difference $\triangle p O_{2}(\mathrm{~Pa})$ of oxygen across both sides of the membrane. The proportionality constant $P$ is called the permeability coefficient $\left(\mathrm{m}^{3} \cdot \mathrm{m} / \mathrm{m}^{2} \cdot \mathrm{s} \cdot \mathrm{Pa}\right)$. The method measures the increase in the partial pressure of oxygen $\left(p_{2}\right)$ over time in an initially oxygen-evacuated chamber. Care must be taken that, even upon reaching steady-state permeation, the partial pressure $p_{2}$ of the permeated gas, oxygen, remains negligibly small compared to the partial pressure of the gas on the other side of the membrane, i.e., the atmospheric air (i.e., $\left.p_{2}<<p_{1}\right){ }^{20}$ 
Steady state is reached when the increase in $\mathrm{pO}_{2}$ over time is linear, indicating the constant entry of oxygen through the wood. The slope of this line is the value of the OTR, which indicates the flow of oxygen permeating the wood over a given time and is usually expressed in $\mathrm{mg} / \mathrm{L} \cdot y e a r$. To express the OTR in $\mathrm{g} / \mathrm{L} \cdot \mathrm{year}$, a $225 \mathrm{~L}$ barrel was considered to have an internal wood surface of $2.01 \mathrm{~m}^{2}$.

Assay protocol. At each of the eleven times the eight samples were simultaneously tested in a measurement device equipped with eight independent wood sample chambers. The measurement device was tested according to previously published instructions to ensure proper operation. ${ }^{19}$ Before every assay, the system was maintained under these conditions for at least $2 \mathrm{~h}$ in order to avoid the interference of desorption phenomena from the interior to the exterior of the oak samples, described by other authors in porous materials. ${ }^{21}$ In this regard, the oxygen partial pressure gradient inside the wood was achieved much sooner, similar to what occurs under conditions of aging in barrels, as stated in a previous study. ${ }^{10}$ For this work, each chamber was filled with an oxygen-free model wine propelled with nitrogen (99.9992\%) (Carburos Metálicos, Barcelona, Spain). To guarantee that no wood compounds in the liquid were consuming oxygen, a new model wine (pure water and ethanol at $14 \% \mathrm{v} / \mathrm{v}, \mathrm{pH} 3.5$ ) was used in each of the eleven tests carried out on each of the 8 wood samples, avoiding oxygen scavengers, to determine oxygen transfer through the oak. All of the assays were performed in a climate-controlled barrel room, and the temperature of the eight holders was kept constant $\left(15 \pm 0.01^{\circ} \mathrm{C}\right)$ by a Julabo FP40-ME thermostatic bath (Seelbach, Germany).

Statistical analysis. The data were collected using Microsoft Excel ${ }^{\circledR} 2013$ software (Redmond, WA) and Statgraphics Centurion XVI (Statpoint Technologies, Warrenton, VA).

\section{Results and discussion}

The aging of wine in barrels primarily requires the conditioning of barrels according to cooperage instructions. Subsequently, the barrels are filled with wine, which begins the soaking of the wood. During the aging process, one side of the wood contacts air and the other wine, which results in a progressive increase in $\mathrm{MC} \%$ due to the advance in the moisture front from the inside to the outside of the barrel. The wetting process of wood, besides depending on the type of oak and the processes performed in the cooperage, is also affected by humidity and environmental temperature. ${ }^{22}$ This wetting causes changes in the wood that directly affect its ability to transmit oxygen. ${ }^{11,23}$ Therefore, the OTR was evaluated in eight types of wood under aging conditions, i.e., with one of the wood faces in contact with air and the other in contact with model wine, at eleven different times within an aging process of $210 \mathrm{~d}$. It was possible to carry out measurements in a test reproducing barrel conditions, using a previously described device. ${ }^{18}$ This device measures the oxygen transmission rate of wood assuming conditions in which the wood is considered to be a porous solid partially flooded by a liquid. In addition, the average weight increase of each of the eight types of wood was calculated, evaluating their weight gains at different times of the 210-d assay.

Evaluation of the OTR of different oak woods. The change in the OTR in the eight types of toasted oak after a total wetting time of $210 \mathrm{~d}$ indicates that the ability of the wood to transfer oxygen significantly decreases over time. Figure 21 shows the results obtained for 
each of the woods studied over the time that they were in contact with the model wine. It must be remembered that the samples were degassed before starting each test, so the results exclusively show the entry of oxygen through the wood at each time analyzed. Annual OTR is calculated using the measurements made on each wood at each time up to the 210 $\mathrm{d}$, on the basis of which it is extrapolated to $365 \mathrm{~d}$. These data allow the annual oxygen entry rate through the wood to the wine aging in a barrel to be determined. The measured OTR results are shown in Table 2.

Global analysis of all the woods showed that French oak has an annual measured OTR of $12.34 \mathrm{mg} / \mathrm{L}$, which is significantly higher than that of American oak with $9.51 \mathrm{mg} / \mathrm{L}$ $(\mathrm{p}=0.0366)$. Therefore, the French oak woods, on average, permit $30 \%$ more oxygen delivered to the wine compared with aging in the American ones. With respect to the importance of the grain of the wood to the OTR, no statistically significant differences were recorded when evaluating the fine grain American oak woods (Kentucky 2.3, Missouri 1.6 and Minnesota 1.06) in comparison with the medium grain ones (Kentucky 4, Missouri $3.5)(p=0.8480)$. Nor were any differences found between very fine French woods (Allier 1.2 and Centre 1.1) and fine grain ones (Centre 1.4) $(\mathrm{p}=0.5994)$.

A previous study showed that the oxygen entry rate through wood decreases over time following a non-linear tendency; ${ }^{7}$ therefore the variation in the OTR of each wood over aging time was adjusted in accordance with a logarithmic model. Table 2 shows the results obtained from fitting the data of measured OTR from the different oak staves according to the best logarithmic time-dependent power equation, $(\log O T R=a+b \sqrt{t})$ where OTR expressed in $\mathrm{mg} / \mathrm{L}$ and $t$ is aging time in $\mathrm{d}$. The usefulness of the different kinetic models was assessed by the values of $R_{a d j}{ }^{2}$ between 0.9943 and 0.8106 . The oxygen rates estimated using the proposed model, presented in Table 2 as calculated OTR, have been observed to differ slightly between 1.7 and $8 \%(0.17$ and $0.8 \mathrm{mg} / \mathrm{L} . \mathrm{y})$ from the real rates measured. This is due to the fact that the measured rates were calculated for each time between the consecutive tests with the average between these tests, and those estimated with the model evolve daily with aging time.

This trend, observed for the OTRs of wood pieces from the staves of the constructed barrel, is consistent with previous results, in which an overall decrease in OTR was observed in barrels with increasing aging time. ${ }^{7}$ That study proposed that the overall OTRs of the barrels (resulting in oxygen entering through the wood and the joints) were dynamic, not constant, and followed a time dependent trend. This result was obtained under aging conditions, analyzing 27-mm thick wood samples that contact liquid on one side and atmosphere on the other. The results obtained are similar to those described by Vivas et al. ${ }^{9}$ when evaluating dry and thinner $(2 \mathrm{~mm})$ woods just once and under conditions different to that in wine barrels. It is noteworthy that the data presented here were obtained from analyzing eight types of wood, each on 11 occasions in succession, that is, they reflect the trends in the OTR over $210 \mathrm{~d}$ (Figure 2).

The structure of the wood and thus its properties, especially its density, plays a fundamental role in its OTR. It has been found that lighter, less dense woods let more oxygen through, resulting in higher OTRs. Bearing in mind the density data presented in Table 1 and the OTRs in Table 2, it has been confirmed that there is a significant correlation between density and OTR, both measured ( $\left.\mathrm{r}_{\text {total }}=-0.8454, \mathrm{p}=0.0082\right)$ and calculated $\left(\mathrm{r}_{\text {total }}=-0.9060\right.$, $\mathrm{p}=0.0019$ ). However separately by species, in the case of the American woods, the relationship between density and measured OTR is not significant in either that measured 
$\left(r_{\text {total }}=-0.6859, p=0.2011\right)$ or that calculated $\left(r_{\text {total }}=-0.7219, p=0.1685\right)$ in oak woods. In the case of the French woods, the relationship between density and measured OTR is not significant, $r_{\text {total }}=-0.9903, p=0.0889$ for measured OTR and $r_{\text {total }}=-0.9485, p=0.2053$ for that calculated. Therefore, in addition to density there are other factors which define the possible transfer of oxygen through wood, with the manner in which the wood is impregnated with wine a determinant aspect in OTR modification. ${ }^{11}$

Evaluation of the impregnation of different oak woods. Each piece was weighed to determine the weight gain due to impregnation at different times of the trial and to calculate the increase in weight with respect to the initial weight. The results show that the oxygen transfer rate of wood changes with its degree of impregnation, confirming what was hypothesized and confirmed previously in wood. . $^{4,9,11}$

Figure 3 shows the weight gain by wine impregnation of each of the tested oak wood samples with respect to their initial weights over their time of contact with the model wine. As shown in Figure 3, as the model wine penetrates the first layers of wood, oxygen permeation dramatically decreases, especially in the early $d$ of aging. The decrease can be explained by water entering the wood structure. Dry wood is defined by two media (wood and air), and wet wood becomes a flooded porous solid defined by three media (wood, air, and liquid). This phenomenon can explain the decrease in OTR because the oxygen diffusion coefficient in water is much lower than that in air. It has been found that French oak woods increase their weight faster (Figure 3) than American oak woods, increasing their weight by $5.5 \%-7 \%$ with respect to their initial weights due to impregnation, compared to an increase of $2.5 \%-4.5 \%$ found in American woods. This result can be related to the high level of tyloses of American woods compared to French ones. Tyloses are expansions of parenchymal cells adjacent to vessels, and they markedly increase the resistance to fluid flow. It can also be observed (Figure 3) that medium grain American woods from Kentucky 4 and Missouri 3.5 are impregnated to a more significant percentage than the fine-grain ones, indicating that they absorbed proportionally more model wine despite being denser $\left(825 \mathrm{~kg} / \mathrm{m}^{3}\right.$ and $850 \mathrm{~kg} / \mathrm{m}^{3}$, respectively) (Table 1). This study coincides with what was observed in oxygen entry as the densest wood accumulates more liquid in the case of equal $\mathrm{MC}$ producing the decrease in oxygen diffusion.

The results show that even though French woods are more impregnated with model wine, they let more oxygen enter, a seemingly contradictory result with what has been presented thus far. To explain these results, we must consider how water is distributed in the wood. On the one hand, water permeates cell membranes because it binds to the molecules that form the cell wall (this constitutive water cannot be increased without destroying the wood), and it impregnates cell membranes because it inserts itself into the cavities (elemental inter-microfibrils and intra-microfibrils) of the cell wall structure (i.e. bound water). On the other hand, water can fill the cavities of the cell membranes (lumens); this water (called free or capillary water) is not linked to the structure of the wood and only physically occupies the void space, and it produces no dimensional variation in the wood. The limiting amount of free water that the wood is able to retain depends on the volume of the cavities of the wood. When cell membranes contain the maximum amount of constitutive water and there is only air in the cavities of the cell, the wood is at its limit of hygroscopicity, i.e. the fiber saturation point (FSP), which is $29-30 \%$ at $20^{\circ} \mathrm{C} .{ }^{24}$ Wood starts to impregnate from the face of the stave in contact with the liquid inside the barrel. Logically, the distribution of the MC\% across the thickness of the stave is not uniform, and an $\mathrm{MC} \%$ profile is produced within the stave throughout its thickness from the inner side 
in contact with the wine outwards. In the impregnation process, the moisture content of the wood increases, eventually reaching its fiber saturation point, at which point the moisture is above $30 \%{ }^{22}$ From that moment, water (from the model wine) will be found as free water, flooding the void space in the wood (porosity) and decisively reducing the oxygen transfer rate of the wood. The maximum quantity of water which can be forced into a wood specimen of known specific gravity and moisture content may be calculated from the porosity. The MC for each type of wood that represents the full saturation of the porosity is $M C_{\max }$ and can be directly determined by (Eqn. 3$)^{13}$

$$
M C_{\text {max }}=\frac{100}{G}-65.3
$$

In order to determine the mass of water to reach full saturation of the void space equation 4 , described by Siau ${ }^{13}$ which calculates water retention on a basis of the fraction of voids filled $\left(F_{V L}\right)($ Eqn. 4$)$, was used:

$$
F_{V L}=\frac{W_{L}}{\rho_{L} \cdot v_{a} \cdot V}
$$

where $W_{L}=$ mass of liquid, $\rho_{L}=$ density of liquid, $V_{a}=$ porosity before impregnation and $V$ $=$ volume of wood.

Moisture distribution within the stave. With the aim of determining the relationship between the thickness of wood that is above its FSP and the oxygen transfer rate of the wood a concurrent experiment was carried out. Thickness was determined at four time points during the process of model wine aging $(7,21,42$ and $105 \mathrm{~d})$ with four of the eight woods: two Quercus alba and two Quercus petraea. For each type of wood, a MC\% profile was constructed, analyzing the wood moisture at different depths. Stability in the humidity profile of the oak stave in a barrel was considered to have been reached after $105 \mathrm{~d}^{11,22}$ The thickness of wood with moisture higher than $30 \%$ at each of the times evaluated is called the thickness of flooded wood, expressed in $\mathrm{mm}$, and was extracted from the moisture profile of four woods (Minnesota 1.05, Missouri 1.6, Allier 1.2, and Centre 1.4). Thus, for example, Figure 4 shows the MC\% profile obtained for French Allier 1.2 oak wood, where the flooded wood front can be seen to advance over aging time flooding half a millimeter every seven $\mathrm{d}, 1.6 \mathrm{~mm}, 3.6 \mathrm{~mm}$ and $4.3 \mathrm{~mm}$ in the following 21,42 and 105 d.

The wood thickness containing free water clearly affects OTR, but to discover in detail if, in addition to wood thickness with free water, the level of free water has any influence on oxygen diffusion flux, a new variable was calculated (eMC, expressed in $\mathrm{mm}$ ) That is the product of the thickness of the flooded layer $(\% \mathrm{MC}>\mathrm{FSP})$ and of its average $\% \mathrm{MC}$ between FSP and $M C_{\max }$, (different for each wood), i.e. the average free water that exists in that thickness (Figure 5). The relationship between the influence over measured OTR of the wood at each time (Figure 2) and the amount of water in the flooded layer of the stave in contact with the wine is shown in Figure 6 . In all of the cases, the regression lines were found to be significant for both American and French oak woods and similar to what was recorded in previous work. ${ }^{11}$ Furthermore, the correlation was found to be negative, so a greater amount of water in the layer of flooded wood (eMC) implies a lower OTR (expressed in mg/L.d). For the American oak woods, Minnesota 1.05 oak wood (density $\left.734 \mathrm{~kg} / \mathrm{m}^{3}\right)$ has a logarithmic trend of OTR $=-21.58 \ln \mathrm{eMC}+18.809\left(\mathrm{R}^{2}=0.9926\right)$ between the increased flooded thickness and the decreased oxygen transmission rate with aging time, similar to Missouri 1.6 oak wood (density $735 \mathrm{~kg} / \mathrm{m}^{3}$ ), which follows the equation OTR $=-17.2 \ln$ eMC+28.951 $\left(\mathrm{R}^{2}=0.8169\right)$. The results found for the French woods indicate that the oxygen transfer rate follows a logarithmic trend with an increasing amount 
of water in the flooded thickness $(\mathrm{mm})$ : OTR $=-40.24 \ln$ eMC+81.172 $\left(\mathrm{R}^{2}=0.9564\right)$ for Allier 1.2 wood, OTR $=-17.08 \ln$ eMC+62.452 $\left(\mathrm{R}^{2}=0.9461\right)$ for Centre 1.4 wood.

French woods are lighter (average density of $568 \mathrm{~kg} / \mathrm{m}^{3}$, Table 1) than American ones (average density of $765 \mathrm{~kg} / \mathrm{m}^{3}$, Table 1); thus, when French woods reach their FSPs and have moistures of $30 \%$ (representing the weight of water relative to the dry weight), they contain less water (ranging from 160 to $180 \mathrm{~kg} / \mathrm{m}^{3}$ ) than American ones, which contain between 220 and $247 \mathrm{~kg} / \mathrm{m}^{3}$. Furthermore, French woods have higher porosities $(63.2 \%$ $\pm 1.65)$ than American ones $(51.0 \% \pm 0.05)$, which are derived from their lower densities. Therefore, French woods are expected to transfer more oxygen than American ones, even though the flooded wood thickness $(\mathrm{MC} \%>\mathrm{FSP})$ is greater, because the proportion of air in the flooded space $(36.3 \% \pm 0.97)$ is $30 \%$ higher than that of the American woods $(27.4 \% \pm 0.04)$, explaining the apparent contradiction mentioned earlier.

It has been found that at $105 \mathrm{~d}$ the studied American woods have flooded thicknesses (with MC above $30 \%$ ) of $3 \mathrm{~mm}$ the Minnesota 1.05 wood while Missouri 1.6 wood has flooded $4 \mathrm{~mm}$ and both allow an oxygen flow of $20 \mathrm{mg} / \mathrm{L} \cdot$ year (Figure 6). Given that both woods have the same density, the difference could be explained by the difference in the grain because the larger-grain wood (Missouri 1.6) has a flooded layer higher than the smallergrain wood (Minnesota 1.05). This result may be related to the tyloses that abound in American woods $(Q . a l b a)$, especially in the early (spring) wood that markedly increases resistance to fluid flow. ${ }^{25}$ These tyloses may explain that the fine-grain wood provides an increased resistance to wine model flooding due to having a greater proportion of early wood and more tyloses.

In the French woods $67.7 \% \pm 1.22$ of the porosity is occupied by free water, while in the American ones the free water occupies $79.3 \% \pm 1.12$. This explains why the French woods have higher OTRs as they contain a smaller quantity of water and the oxygen passes through $27 \mathrm{~mm}$ of wood with the porosity partially filled with water, the rest being gas (where the oxygen disseminates $10^{5}$ times faster than in liquid), and therefore the oxygen disseminates more easily. However, American woods are denser and less porous so have practically all their porosity full of free water, which means that the oxygen takes $10^{5}$ times longer to pass through the $27 \mathrm{~mm}$ of wood. This effect has also been seen to be more marked over aging time, demonstrating a greater difference between the OTR of French and American woods (Figure 6).

In summary, this study confirmed that oxygen entry through oak wood, even when it is flooded and its OTR decreases with aging time, is mainly due to the impregnation of the wood. The lower density of French oak wood compared to American oak causes its higher oxygen transfer rate because of its role in the impregnation process, accumulating less liquid in the case of equal MC. For the first time, it has been found that under similar aging conditions to those in barrels, the French oak wood staves provided more oxygen than those of American oak. Additionally, it has been confirmed that grain plays a role in OTR in the measured Quercus alba woods, so finer-grained American woods let in more oxygen than the same wood with a medium grain, characteristics that are maintained throughout the study.

\section{Corresponding authors}

*Corresponding author (Tel: +34-979-108384; Fax: +34-979-108302: E-mail: inevares@iaf.uva.es) 


\section{Funding}

This work was financed by the Ministerio de Ciencia e Innovación (Ministry for Science and Innovation) and FEDER funds (AGL2011-26931, AGL2014-54602-P) and by Junta de Castilla y León (Regional Government of Castilla y León, VA028U16 and VA124U14) of Spain.

\section{Notes}

The authors declare no competing financial interest.

\section{Acknowledgements}

The authors would like to acknowledge C. González-Muñoz for the sample preparation. The authors express great appreciation to Tonelería Duero (Aranda de Duero, Spain) for their collaboration.

\section{References}

(1) Piracci, A.; Bucelli, P.; Faviere, V.; Giannetti, F.; Lo Scalzo, R.; Novello, E. Frammenti legnosi e vino: alcune specifiche tecniche di chips e staves di rovere. L'Enologo 2001, 7-8, 97-106.

(2) Renouf, V.; Qiu, Y.; Klebanowski, H.; Monteau, A.-C.; Mirabel, M. L`apport d'oxygène durant l'èlevage en fûts. L'importance du phénomène de désorption de l'oxygène contenu dans le bois. Rev. des Oenologues 2016, Octobre, 52-55.

(3) Vivas, N.; Saint-Cricq de Gaulejac, N. The useful lifespan of new barrels and risk related to the use of old barrels. Aust. New Zeal. Wine Ind. J. 1999, 14, 37-45.

(4) Singleton, V. L. Maturation of Wines and Spirits - Comparisons, Facts, and Hypotheses. Am. J. Enol. Vitic. 1995, 46, 98-115.

(5) Vivas, N.; Nonier, M. F.; Vivas de Gaulejac, N.; Vivas de Gaujelac, N. Reactions and occurrence of wine polyphenol evolution during the oxidative process in oak. Aust. New Zeal. Wine Ind. J. 2005, 20, 61-62.

(6) Vivas, N. Modélisation et calcul du bilan des apports d'oxygène au cours de l'élevage des vins rouges. IV - Elevage des vins rouges en conditions d'oxydations ménagées controlées. Progrès Agric. Vitic. 1999, 116, 305-311.

(7) del Alamo-Sanza, M.; Nevares, I. Recent Advances in the Evaluation of the Oxygen Transfer Rate in Oak Barrels. J. Agric. Food Chem. 2014, 62, 8892-8899.

(8) Denny, M. W. Air and water : the biology and physics of life's media; Princeton University Press: Princeton, N.J., USA, 1993.

(9) Vivas, N.; Debeda, H.; Menil, F.; Vivas de Gaulejac, N.; Nonier, M. F. Mise en évidence du passage de l'oxygène au travers des douelles constituant les barriques par l'utilisation d'un dispositif original de mesure de la porosité du bois. Premiers résultats. Sci. Aliments 2003, 23, 655-678.

(10) Nevares, I.; Crespo, R.; González, C.; del Alamo-Sanza, M. Imaging of oxygen permeation in the oak wood of wine barrels using optical sensors and colour camera. Aust. J. Grape Wine Res. 2014, 20, 353-360.

(11) Nevares, I.; Mayr, T.; Baro, J. A.; Ehgartner, J.; Crespo, R.; Alamo-Sanza, M. Ratiometric Oxygen Imaging to Predict Oxygen Diffusivity in Oak Wood During Red Wine Barrel Aging. Food Bioprocess Technol. 2016, 9, 1049-1059.

(12) International Standard Organization. ISO 13061-2:2014 - Physical and mechanical properties of wood -- Test methods for small clear wood specimens -- Part 2: Determination of density for physical and mechanical tests. ISO 2014, p 5. 
(13) Siau, J.F. Wood-Influence of Moisture on Physical Properties; Dept. of Wood Science and Forest Products, Virginia Polytechnic Institute and State University: Blacksburg, VA, 1995.

(14) International Standard Organization. 13061-1:2014 Physical and mechanical properties of wood - Test methods for small clear wood specimens - Part 1: Determination of moisture content for physical and mechanical tests. ISO 2014, p 4.

(15) del Alamo-Sanza, M.; Pando, V.; Nevares, I. Investigation and correction of the interference of ethanol, sugar and phenols on dissolved oxygen measurement in wine. Anal. Chim. Acta 2014, 809, 162-173.

(16) Mejane, J. V; Debailleul, M.; Lecerf, J. Étude sur la solubilité de l'oxygène dans 1'alcool. Ind. Aliment. Agric. 1973, 90, 719-727.

(17) Qiu, Y. Phénomènes de transfert d'oxygène à travers la barrique, Ph.D. Thesis Université de Bordeaux, 2015. (https://tel.archives-ouvertes.fr/tel-01340867; accessed 12-07-2016).

(18) Del Alamo, M.; Nevares, I. PCT/ES2012/070084 Device for measuring the permeability and diffusivity of gases in porous materials and method for measuring said parameters using the device, 2012.

(19) Nevares, I.; del Alamo-Sanza, M. Oak Stave Oxygen Permeation: A New Tool To Make Barrels with Different Wine Oxygenation Potentials. J. Agric. Food Chem. 2015, 63, 1268-1275.

(20) Piringer, O. G. Permeation of gases, water vapor and volatile organic compounds. In Plastic packaging materials for food: barrier function, mass transport, quality assurance, and legislation; Piringer, O. G., Baner, A. L., Eds.; Wiley-VCH: Weinheim ; New York, 2000; p 250.

(21) Skouroumounis, G.; Waters, E. Oxygen ingress into bottled wines. AWRI Tech. Rev. 2007, 170, 13-19.

(22) Ruiz de Adana, M.; López, L. M.; Sala, J. M. A Fickian model for calculating wine losses from oak casks depending on conditions in aging facilities. Appl. Therm. Eng. 2005, 25, 709-718.

(23) Hansmann, C.; Gindl, W.; Wimmer, R. Permeability of wood - a review . Wood Res. 2002, 47, 1-16.

(24) Glass, S.V.; Zelinka, S. L. 2010. Moisture relations and physical properties of wood. In Wood handbook: wood as an engineering material; U.S. Dept. of Agriculture, Forest Service, Forest Products Laboratory: Madison, WI 2010: p. 508.

(25) Siau, J. F. Transport processes in wood; Springer-Verlag: Berlin ; New York, 1984. 
Table 1. Oak Wood Characteristics.

\begin{tabular}{cccccccc}
\hline Wood Name & Wood Species & Origin & Grain $^{\mathrm{b}}$ & $\begin{array}{c}\text { Real } \\
\mathrm{Grain}^{\mathrm{c}}\end{array}$ & $\begin{array}{c}\text { Density } \\
\left(\mathrm{kg} / \mathrm{m}^{3}\right)\end{array}$ & $\begin{array}{c}\text { Porosity } \\
(\%)\end{array}$ & $M_{\max }(\%)$ \\
\hline Kentucky 2.3 & Quercus alba & Kentucky & tight & 2.3 & 682 & 55.47 & 81.33 \\
Kentucky 4 & Quercus alba & Kentucky & medium & 4 & 825 & 46.13 & 55.91 \\
Missouri 1.6 & Quercus alba & Missouri & tight & 1.6 & 735 & 52.00 & 70.75 \\
Missouri 3.5 & Quercus alba & Missouri & medium & 3.5 & 850 & 44.50 & 52.35 \\
Minnesota 1.05 & Quercus alba & Minnesota & tight & 1.05 & 734 & 52.07 & 70.94 \\
Allier 1.2 & Quercus petraea & Allier & tight & 1.2 & 534 & 65.13 & 121.97 \\
Center 1.4 & Quercus petraea & Center & tight & 1.4 & 601 & 60.75 & 101.09 \\
Center 1.1 & Quercus petraea & Center & very tight & 1.1 & 569 & 62.84 & 110.45 \\
\hline
\end{tabular}

${ }^{a}$ Wood species according to cooperage certification, ${ }^{b}$ grain according to cooperage classification, ${ }^{c}$ grain measured in each oak sample

Table 2. Kinetic Model Used to Explain the Oxygen Transfer Rate Decrease from Oak Staves and Annual Rates for Different Oak Woods.

\begin{tabular}{ccccc}
\hline Oak wood & $\begin{array}{c}\text { Measured } \\
\text { OTR } \\
(\mathrm{mg} / \mathrm{L} . \mathrm{y})\end{array}$ & Regression lines* & $\begin{array}{c}\text { Calculated } \\
\text { OTR } \\
(\mathrm{mg} / \mathrm{L} . \mathrm{y})\end{array}$ \\
\hline Kentucky 2.3 & 11.97 & $\log \mathrm{y}=-1.04-0.24 \mathrm{x}^{-0.5}$ & $\mathrm{R}^{2}=0.9020$ & 11.64 \\
Kentucky 4 & 9.45 & $\log \mathrm{y}=-1.09-0.26 \mathrm{x}^{-0.5}$ & $\mathrm{R}^{2}=0.9379$ & 9.63 \\
Missouri 1.6 & 9.25 & $\log \mathrm{y}=-0.93-0.29 \mathrm{x}^{-0.5}$ & $\mathrm{R}^{2}=0.9162$ & 8.89 \\
Missouri 3.5 & 8.27 & $\log \mathrm{y}=-0.66-0.37 \mathrm{x}^{-0.5}$ & $\mathrm{R}^{2}=0.8106$ & 7.28 \\
Minnesota 1.05 & 8.64 & $\log \mathrm{y}=-0.57-0.35 \mathrm{x}^{-0.5}$ & $\mathrm{R}^{2}=0.9414$ & 8.85 \\
American Oak & $9.51 \pm 1.45$ & & & $9.26 \pm 1.58$ \\
Allier 1.2 & 14.18 & $\log \mathrm{y}=-0.19-0.34 \mathrm{x}^{-0.5}$ & $\mathrm{R}^{2}=0.9352$ & 14.10 \\
Center 1.4 & 10.24 & $\log \mathrm{y}=-0.24-0.37 \mathrm{x}^{-0.5}$ & $\mathrm{R}^{2}=0.9643$ & 11.04 \\
Center 1.1 & 12.60 & $\log \mathrm{y}=-0.17-0.35 \mathrm{x}^{-0.5}$ & $\mathrm{R}^{2}=0.9291$ & 13.38 \\
French Oak & $12.34 \pm 1.98$ & & & $12.84 \pm 1.60$ \\
\hline
\end{tabular}




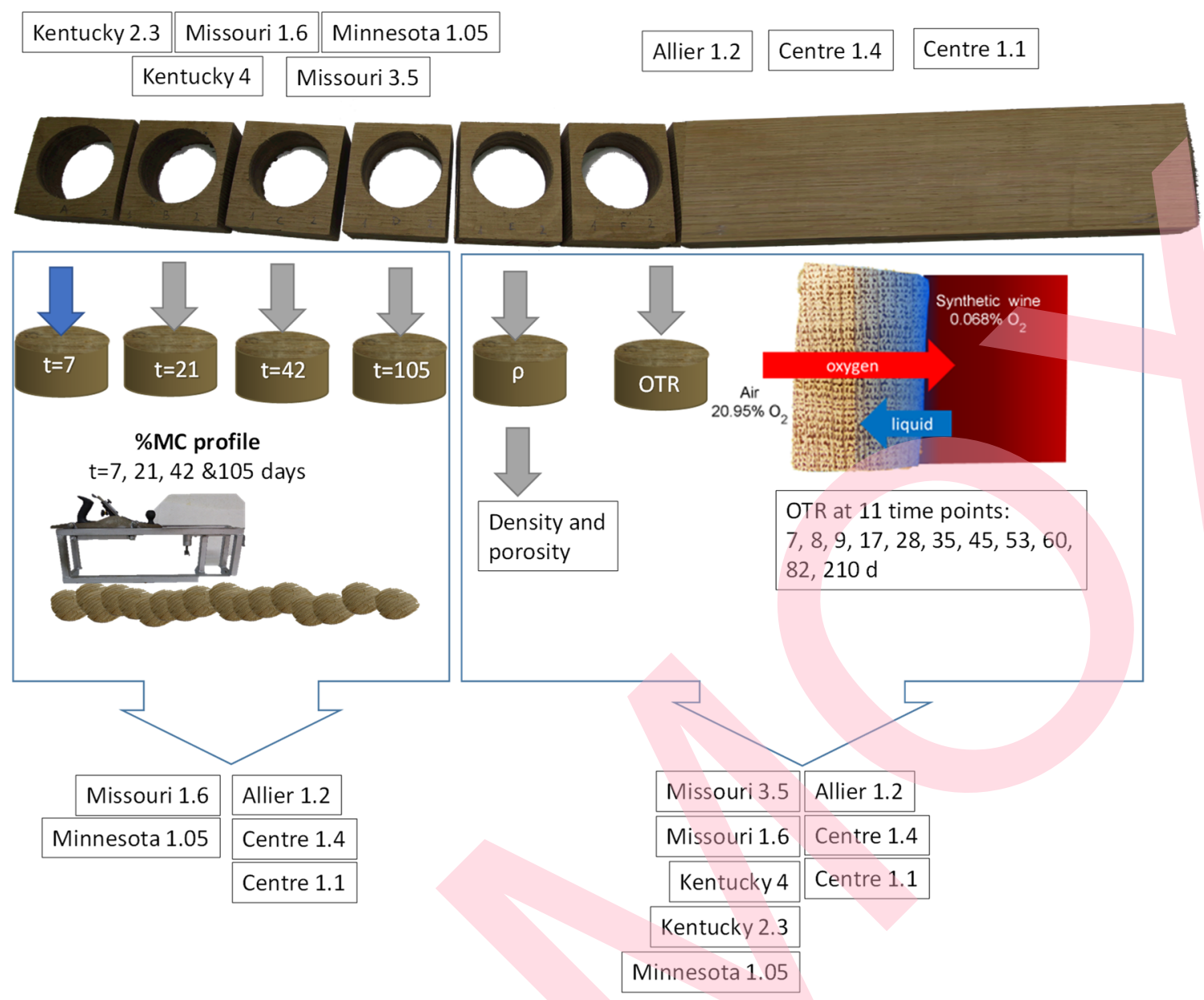

Figure 1. Design of the experiment carried out.

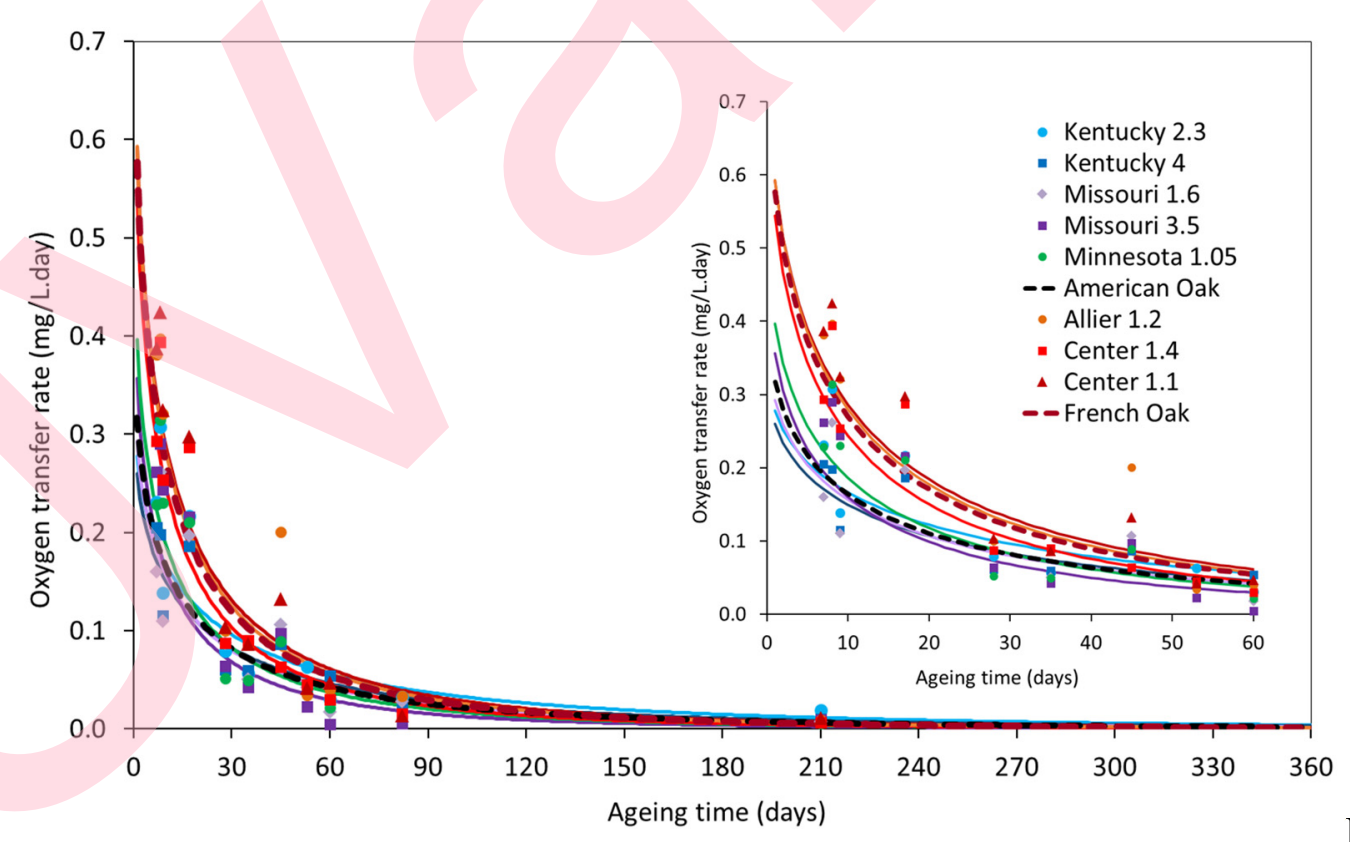

Evolution of the OTR of toasted wood staves of different oaks over the aging time. 


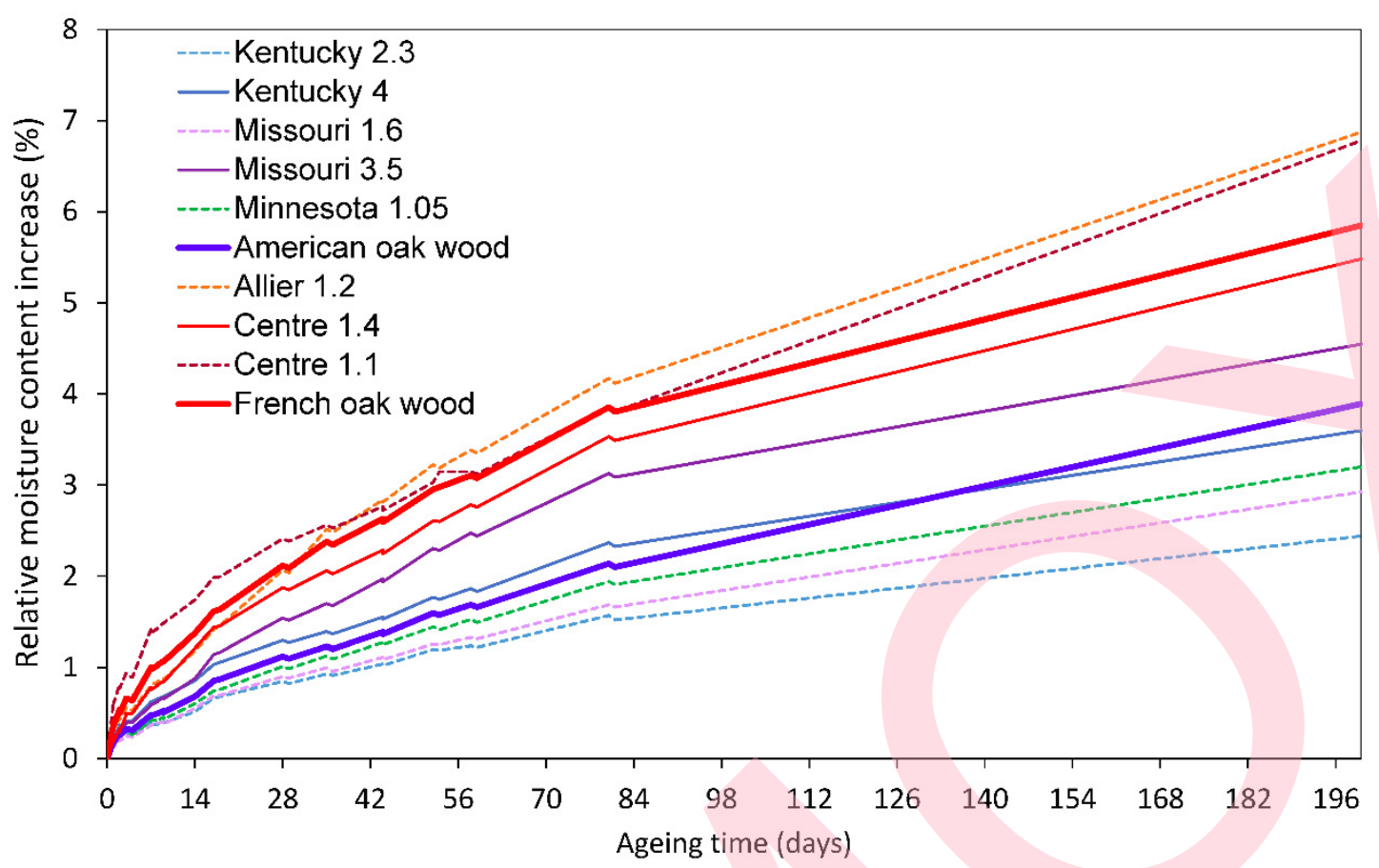

Figure 3. MC gain relative to the initial MC of each of the woods tested over the aging time.

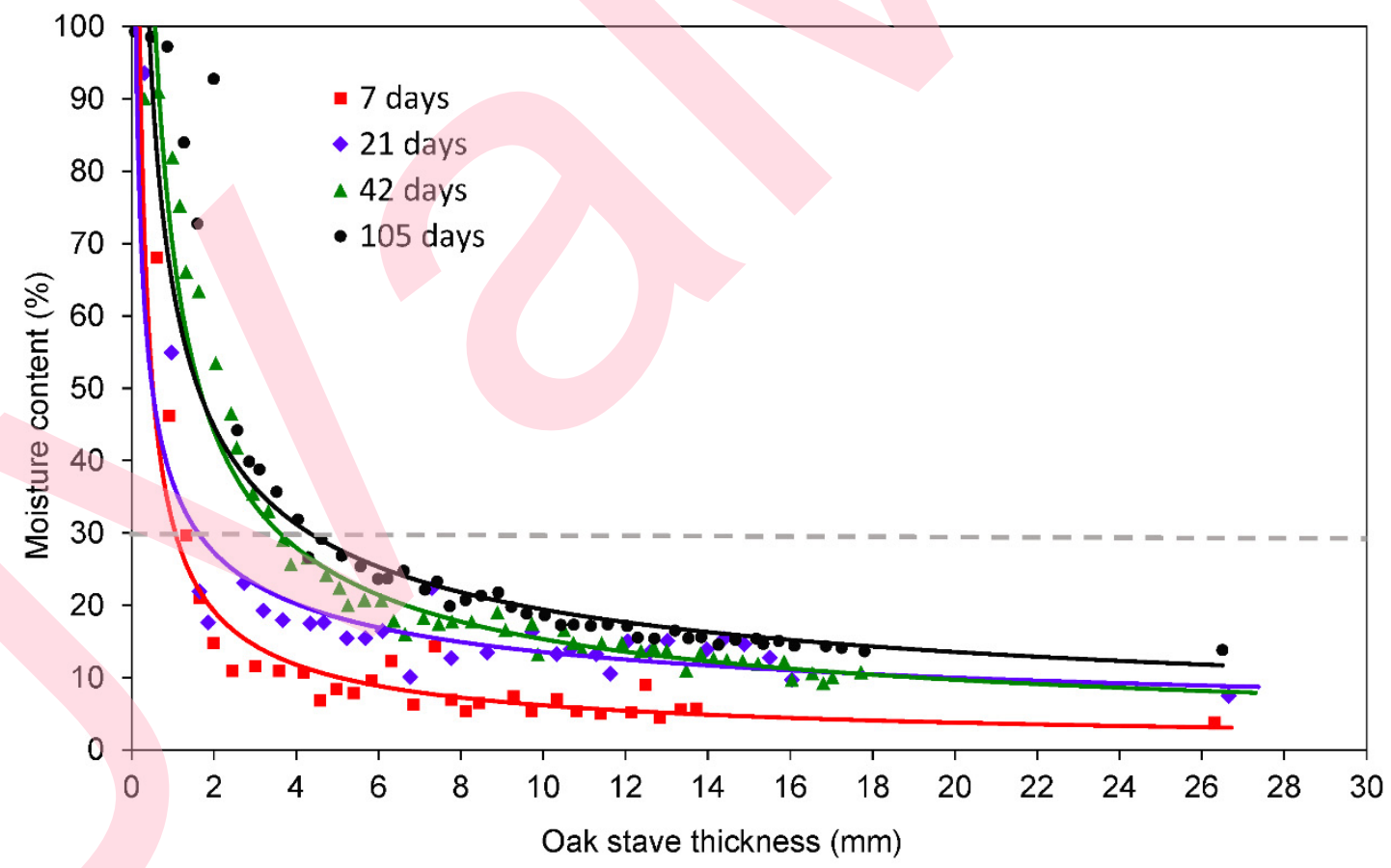

Figure 4. Moisture profiles of Allier 1.4 French oak wood at different moments of aging 


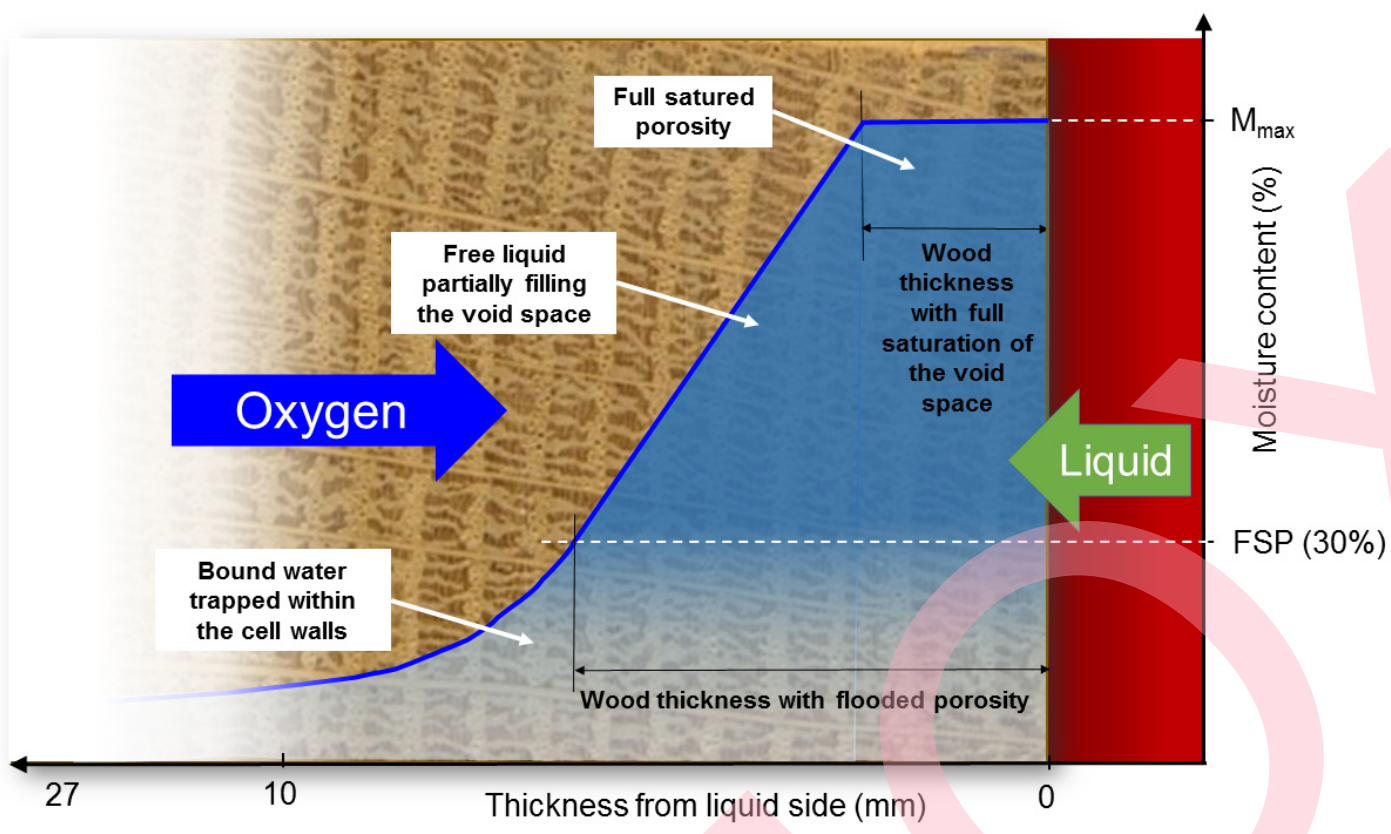

Figure 5. Impregnation model of a stave under barrel conditions
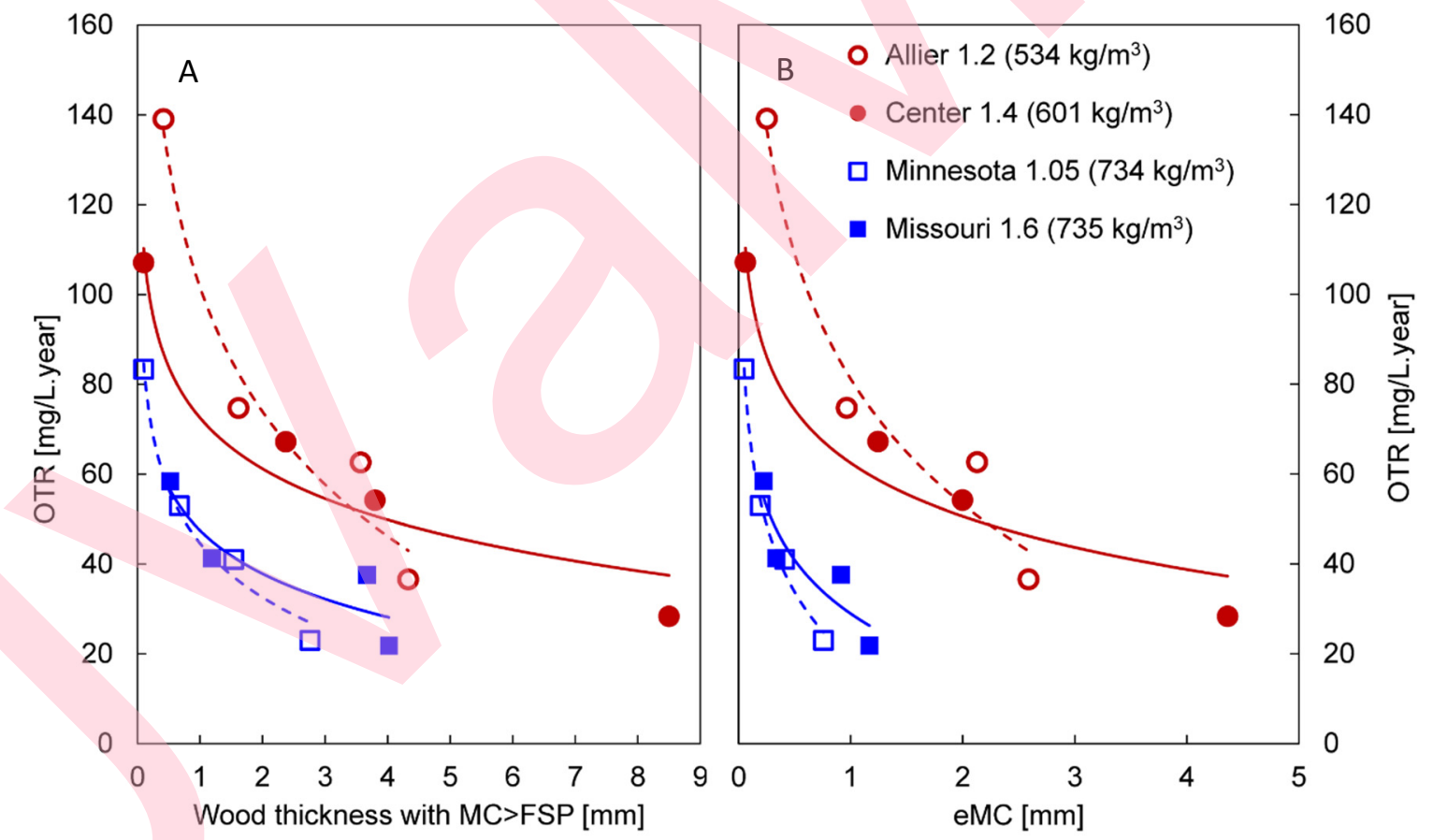

Figure 6. Relationship between the OTR(mg/L.d) of different woods and the thickness of the flooded area $(\mathrm{mm})(\mathrm{A})$ and the average of free water in the flooded layer at each moment $(7,21,45$ and $105 \mathrm{~d})(\mathrm{B})$. 

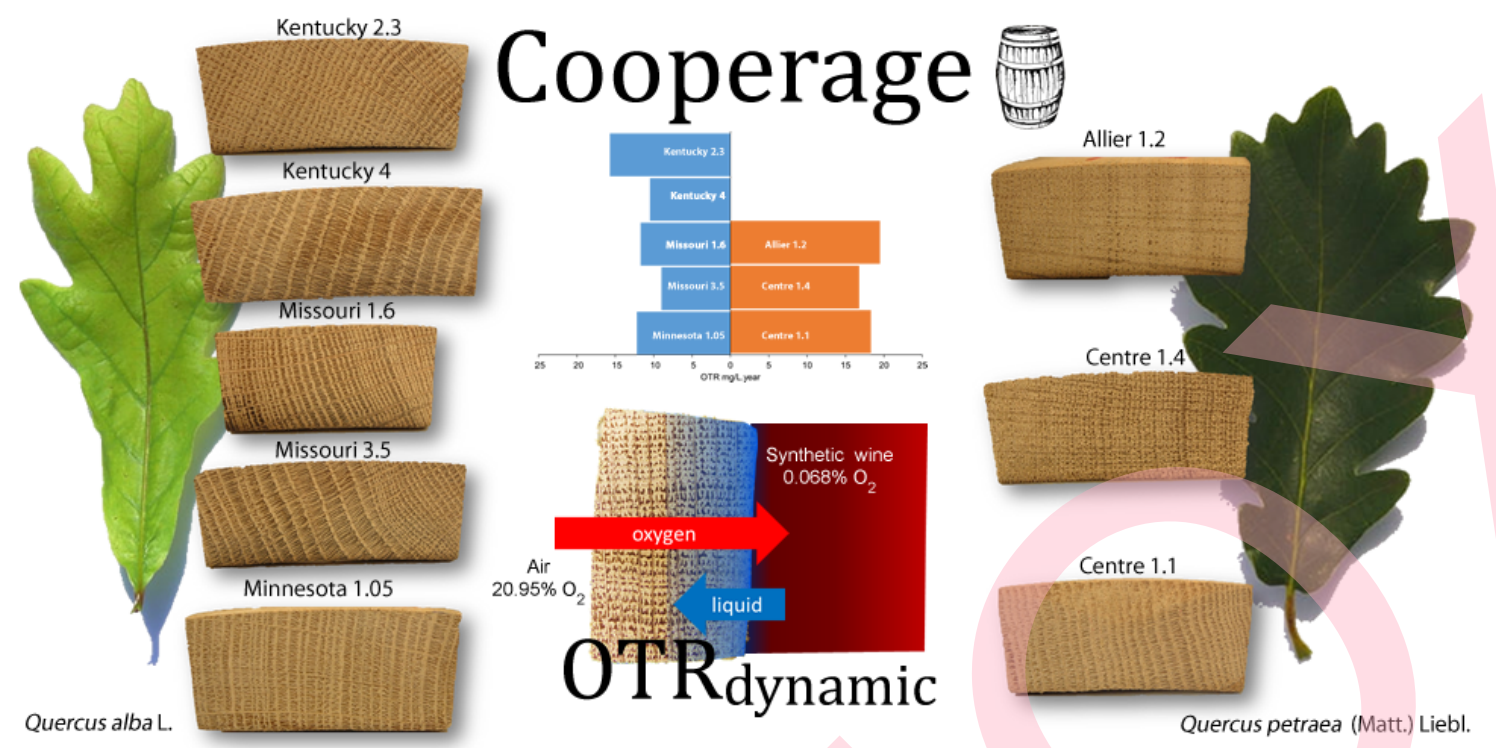